\section{Iron, Porphyrins and Chlorophyll}

IroN is essential for chlorophyll formation ${ }^{1}$. A reasonable hypothesis is that this element acts in the conversion of coproporphyrinogon (COPROgen) to protoporphyrin (PROTO $)^{2,3}$. We have tested this hypothesis and find tho results contrary to expoctation.

The plausibility of what may be called the COPROgen hypothesis stems originally from the finding of Pappenheimer and Johnson ${ }^{4}$ that iron is essential for toxin production by Corynebacterium diphtheriae. Since then it has been found that these bacteria, when iron-deficient, apparently develop a metabolic lesion between COPRO and PROTO and consequently produce large quantities of COPRO; this response is shared by 2 wide variety of miero-organisms. As Granick and Mauzerall ${ }^{5}$ have pointed out, all the available evidence points to the view that free porphyrins (or rather porphyrinogens) are precursors of chlorophyll; it naturally follows that a lesion in the porphyrin pathway would affect chlorophyll synthesis.

We have found that Euglena gracilis is an advantageous test object for studying chlorophyll synthesis. The alga may be grown heterotrophically on glutamate-ethanol ${ }^{6}$ under low light intensity (25-50 ft.-candles) at $25^{\circ}$. After the desired growth has been achieved, the cells are washed and resuspended in $10^{-3} \mathrm{M}$ potassium phosphate buffor, $p H 6 \cdot 8$, and shaken under high light intensity (1,000-1,500 ft.-candles). Under these latter conditions the cells synthesize chlorophyll vigorously, but show no net increase in protein. Thus chlorophyll synthesis may be divorced from growth. Chlorophyll was estimated from the absorbancy at $663 \mathrm{~m} \mu$ of aliquots extracted in 80 per cent acetone.

After the components of the medium were purified, we could demonstrate iron requirements for growth and for chlorophyll formation. At the lowest levels of iron, growth was inhibited (shaded part of Fig. 1). There was also a region of iron concentration throughout which growth was normal (unshaded part of Fig. 1); in part of this region of normal growth, eapacity for chlorophyll formation was decreased. By confining the alga to the rogion of normal growth, we avoided complications due to consequences of growth inhibition.

From the COPROgen hypothesis one can deduce directly that the rate of chlorophyll synthesis in iron deficiency would be limited by the rate of PROTO formation. We expected specifically that the rate of PROTO formation would decrease with decreasing iron content, starting at some critical iron content which would be equal to, or greater than, tho level that was critical for chlorophyll formation.

To test this hypothesis, we incubated suspensions of frozen and thawed Euglena of varying iron content with $2 \times 10^{-4} \mathrm{M}$ porphobilinogen in $0.06 \mathrm{M}$ potassium phosphate, $p \mathrm{H} 6.8$, and estimated the resulting freo porphyrins. Separation was carried out by a modification of the extraction procedure of Dresel and Falk ${ }^{7}$ and the chromatographic method recommended by Eriksen ${ }^{8}$. The several porphyrin components were eluted and the amounts detormined spectrophotometrically at their Soret peaks. No unusual accumulations of COPRO were observed at any of the iron-levels reported here. On the contrary, the rates of COPRO formation decreased slightly with decreasing cell iron. At the same time, the iron-deficient cells, although defective in their capacity to form chlorophyll, produced PROTO at rates equal to or greater than the iron-sufficient controls (Fig. 1).

From the COPROgen hypothesis we expected that the rates of PROTO formation would decreaso with decreasing iron concentration. Our results are clearly at variance with these expectations. While one can imagine a variety of ad hoc modifications to make tho hypothesis fit the data, we believe that the COPROgen hypothesis is unlikely to prove correct.

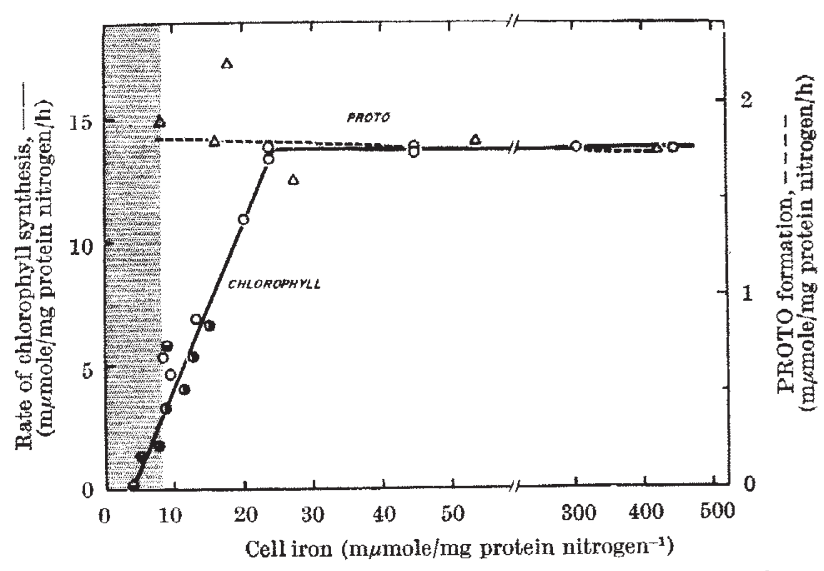

Fig. 1. Fates of chlorophyll and protoporphyrin formation at varying levels of cell iron. The different symbols represent data from separate experiments. The PROTO curve and the rising part of
curve are least mean square regressions

There are hypotheses assigning the action of iron to ALA formation directly or indirectly. Our experiments do not bear on these alternative suggestions.

We thank Drs. W. R. Robbins and H. E. Clark for their suggestions and help throughout the course of this work, and Dr. Samuel Granick for advice. We also wish to thank Dr. Granick for a purified preparation of PROTO and Dr. S. F. MacDonald for gifts of porphobilinogen.

This work was supported in part by grant No. G9815 from the National Science Foundation to Dr. Robbins.

$$
\text { E. F. KARALI }
$$

C. A. Price

Department of Plant Physiology,

Rutgers, The State University,

New Brunswick, New Jersey.

${ }^{1}$ Gris, E., C.R. Acad. Sci., Paris, 19, 1118 (1844).

${ }^{2}$ Lascelles, J., Biochem, J, 62, 78 (1956).

3 Townsley, P. M., and Neilands, J. B., J. Biol. Chem., 224, 695 (1957).

4 Pappenheimer, A. M., and Johnson, S. J., Brit. J. Exp. Path., 18, 239 (1937).

"Granick, S., and Mauzerall, D., in Metabolic Pathways, second ed., edit. by Greenberg, D. M. 525 (Academic Press, 1961).

- Price, C. A., and Vallee, P. I., Plant Physiol., 37, 428 (1962).

; Dresel, E. I. B., and Falk, J. E., Biochem. J., 63, 72 (1956).

8 Eriksen, L., Seand. Clin. Lab. Invest., 5, 155 (1953).

\section{Age of the Baobab Tree}

THE baobab troe Adansonia digitata L. (family Bombacaceae) has been variously estimated as being several hundred to several thousand years old. The French botanist Adanson, aftor whom the tree was named, contended that some specimens were as much as 5,000 years oldx.

It has, however, never been established that the baobab produces annual rings, and such estimates must therefore be regarded as largely guesswork ${ }^{2}$. Since many of these trees are more than $20 \mathrm{ft}$. in diameter and some even in excess of $30 \mathrm{ft}^{1,2}$, tho labour involved in obtaining a complete section and producing a sufficiently smooth surface to count tho rings accurately would in any event bo enormous, and it is doubtful whether this has ever been attempted. Moreover, many of the really larger baobabs have hollow centres due to natural causes or as a result of human intervention ${ }^{1,2}$, thus rendering any attempt at ring-counting impossible.

As a result of bush-clearing operations at Lake Kariba we were fortunate onough to obtain a sample of wood from the hoart of a 15-ft. diameter baobab tree (at a height of about $2 \mathrm{ft}$. above ground-level) which was kindly supplied to us by Mr. F. Swart. The tree was felled during 1960 near the confluence of the Sengwo and Zambesi Rivers ( $16^{\circ} 55^{\prime}$ S.; $28^{\circ} 05^{\prime}$ E.). Samples were also obtained from a point midway between the 